\title{
Coagulation abnormality as a complication of L-asparaginase therapy in childhood lymphoblastic leukemia
}

\author{
Djajadiman Gatot, Keumala Pringgardini, Rulina Suradi
}

\begin{abstract}
Background Bleeding, one of the most common symptoms of acute leukemia in untreated patients, is mostly due to thrombocytopenia as a result of myeloinvasion by leukemic cells. Nevertheless, a further contributory factor for the additional hemorrhagic complication during intensive chemotherapy is the myelosuppressive effect of most active drugs. L-asparaginase, one of the cytostatics used during remission induction therapy for childhood of acute lymphoblastic leukemia (ALL), is widely reported to impair the hemostatic system.

Objective To determine the influence of shorter courses of L-asparaginase (L-Ase) on some of the hemostatic parameters in the treatment of childhood ALL.

Methods A prospective analytical study was carried out in the Department of Child Health, Cipto Mangunkusumo Hospital Jakarta from July 1, 1999 to June 30, 2001 on newly diagnosed ALL patients with normal liver function tests treated according to our national ALL protocol which one of its composition contained 6 instead of 9 injections of L-asparaginase.

Results All of 30 children with ALL included in the study, experienced prolongation of prothrombin time (PT), activated partial thromboplastin time (aPTT), and decreased fibrinogen concentration, markedly during the administration of L-asparaginase. However, none of the patients had additional hemorrhage or evidence of disseminated intravascular coagulation (DIC).

Conclusion The use of shorter courses of L-asparaginase, 6 injections, in the remission induction chemotherapy of childhood ALL in our department may reduce the blood clotting factors without further hemorrhage complication or evidence of DIC [Pediatr Indones 2006;46:46-50].
\end{abstract}

Keywords: L-asparaginase, childhood ALL, coagulation, bleeding

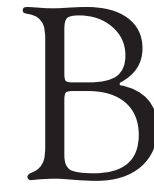

leeding is one of the most common symptoms of acute leukemia and is mostly due to thrombocytopenia, which is almost always a result of bone marrow invasion by leukemic cells. Unlike in acute myeloid leukemia (AML), abnormalities of the blood clotting system underlying the clinical pictures of disseminated intravascular coagulation (DIC) are observed less commonly in acute lymphoblastic leukemia (ALL). ${ }^{1}$ During remission induction chemotherapy with a combination of several active drugs, myelosuppression is always developed and may contribute to further hemorrhagic complication.

L-asparaginase (L-Ase) is an active drug used in combination with other drugs for remission induction therapy of ALL. L-Ase is an antineoplastic enzyme preparation which hydrolyses L-asparagine in the host's blood resulting in the depletion of L-asparagine and therefore stops nutrition supply to specific tumor cells which require this amino acid as an essential nutrient, then consequently, inhibits proliferation of these cells. ${ }^{2-}$ ${ }^{7} \mathrm{~L}$-Ase has long been considered as the most responsible for vascular complications during chemotherapy

From the Hematology Division, Department of Child Health, Medical School, University of Indonesia, Cipto Mangunkusumo Hospital, Jakarta, Indonesia.

Reprint requests to: Djajadiman Gatot, MD, Hematology Division, Department of Child Health, Medical School, University of Indonesia, Cipto Mangunkusumo Hospital, Jakarta, Indonesia. Tel: 62-21-31901170. 
Djajadiman Gatot et al: Coagulation abnormality as a complication of L-asparginase therapy in ALL

for ALL. This drug is also known to be toxic for the liver and pancreas, and is reported to hinder the hemostatic system. ${ }^{8-10}$ Significant reductions of fibrinogen, prothrombin, plasminogen, $\mathrm{a}_{2}$-antiplasmin, antithrombin (AT) III, and activated protein C (PCa) have been consistently reported and is also responsible for abnormal platelet aggregation. $4,7,8-15$

The reduction of AT III level is due to the decrease of its synthesis in the liver. ${ }^{11-13}$ It is also reported that the tissue plasminogen activator and the plasminogen-activator inhibitor are reduced. These abnormalities are responsible for the development of hemorrhage and thrombosis. ${ }^{7,11-13,16}$

In our national ALL treatment protocol, L-Ase is given in 6 courses $\left(6000 \mu / \mathrm{m}^{2}\right)$ by intravenous infusion, modified from the international standard ALL protocol which uses 9 courses of L-Ase. This modification was done since the limited availability and high cost of the drug. In another study, during 1994-2000, the use of this protocol gave remission rate of $81 \%$ in 262 children with ALL which was lower than the international figure (94\%). ${ }^{17}$ The mortality rate was 49 / $262 \%$ during induction remission mostly of the high risk group (31/49\%) due to uncontrolled infection or bleeding. ${ }^{17}$

The purpose of this study was to evaluate coagulation abnormality complicating a shorter course of L-Ase in the remission induction therapy of childhood ALL.

\section{Methods}

This was a prospective analytical study. Thirty newly diagnosed childhood ALL subjects admitted to the Department of Child Health, Cipto Mangunkusumo Hospital, Jakarta during the period of July 1, 1999 to June 30, 2001 were eligible for the study. Due to financial constraint, performed laboratory tests were only transaminases (AST, ALT), fibrinogen, prothrombin time (PT), and activated partial thromboplastin time (aPTT) before commencing treatment.

Our national ALL protocol which contained weekly Vincristin (6 times, i.v., weeks 1-6), weekly Daunomycin (4 times, i.v., weeks 1-4), L-Ase (6 times/ two weeks, i.v., weeks 4-6), dexamethasone orally for 6 weeks and intrathecal triple drug for CNS prophylaxis was used. All drug doses were given according to international ALL protocol standards. To simplify the period of L-Ase administration we used series I for weeks 4-5 and series II for weeks 5-6.

Patients with abnormal transaminases $(>40 \mathrm{~m} \mu$ ) $\mathrm{ml}$ for boys and $>31 \mathrm{~m} \mu / \mathrm{ml}$ for girls), decreased fibrinogen level $(<200 \mathrm{mg} / \mathrm{dl})$ and prolonged PT and aPTT $(\geq 1.5$ fold of normal values) prior to chemotherapy were excluded from the study. Fibrinogen, PT and aPTT were also measured before weeks 4, during weeks 4-6 (series I and II) and after weeks 7 administration of L-Ase. To evaluate whether clotting factors returned to normal after cessation of L-Ase, analysis of delta $(\boldsymbol{\Delta})$ changes on PT, aPTT and the fibrinogen level were performed (Table 4). Data collected were analyzed using SPSS version 10 and with chi-square test and ttest. $\mathrm{P}$ value $<0.05$ was considered significant.

\section{Results}

Subjects consisted of 19 boys and 11 girls. The age ranged between 2.3-12.1 years with median of 5.8 \pm 2.7 years and the majority were in the $3-<5$ years age group as seen in Table 1.

During treatment there were no further or additional bleeding observed in any of the patients and instead, the mucocutaneous bleeding because of thrombocytopenia disappeared gradually with platelets transfusion.

The results of coagulation parameter tests conducted at diagnosis and at each end of series I and II of L-Ase, is shown in Table 2. It is quite obvious that the mean value of PT during series I compared to that at diagnosis was significantly prolonged as well as during the second series. The significant prolongation time, was also seen in aPTT. On the other hand, significant decrease of fibrinogen levels were found during L-Ase treatment.

One week after cessation of L-Ase, weeks 7, the hemostatic parameters were again tested and the

Table 1. Characteristics of subjects

\begin{tabular}{lc}
\hline Variables & Subjects $(\mathbf{n})$ \\
\hline Age & \\
1 mo- $<3$ yrs & 1 \\
$3-<5$ yrs & 15 \\
$5-<12$ yrs & 12 \\
$12-<18$ yrs & 2 \\
Sex & \\
Boys & 19 \\
Girls & 11 \\
\hline
\end{tabular}




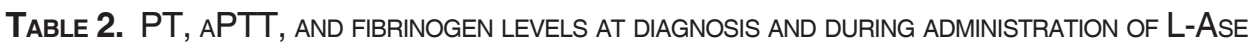

\begin{tabular}{lccccc}
\hline & At diagnosis & Series I & Series II & \multicolumn{2}{c}{ P value } \\
\hline Variables & mean \pm SD & mean \pm SD & mean \pm SD & series I & series II \\
\hline PT $(\mathrm{sec})$ & $9.5 \pm 1.2$ & $18.4 \pm 4.2$ & $23.3 \pm 4.5$ & $\mathrm{P}=0.000$ & $\mathrm{P}=0.000$ \\
aPTT $(\mathrm{sec})$ & $33.4 \pm 2.9$ & $55.1 \pm 13.7$ & $71.0 \pm 12.9$ & $\mathrm{P}=0.000$ & $\mathrm{P}=0.000$ \\
Fibrinogen $(\mathrm{mg} / \mathrm{dl})$ & $92.9 \pm 18$ & $159.9 \pm 42.1$ & $74.3 \pm 12.4$ & $\mathrm{P}=0.000$ & $\mathrm{P}=0.000$ \\
\hline
\end{tabular}

TABLe 3. PT, aPTT, AND fibrinogen LeVels IN SERIES II AND WeEks 7

\begin{tabular}{lccc}
\hline & Series II & After L-Ase (weeks 7) & P value \\
\hline Variables & mean \pm SD & mean \pm SD & \\
\hline PT (sec) & $23.3 \pm 4.5$ & $14.8 \pm 2.7$ & $\mathrm{P}=0.000$ \\
aPTT $(\mathrm{sec})$ & $71.0 \pm 12.9$ & $45.4 \pm 11.4$ & $\mathrm{P}=0.000$ \\
Fibrinogen $(\mathrm{mg} / \mathrm{dl})$ & $74.3 \pm 12.4$ & $142.5 \pm 33.4$ & $\mathrm{P}=0.000$ \\
\hline
\end{tabular}

Table 4. PT, APTT, AND FIBRINOGEN LEVELS AT DIAGNOSIS, DURING (SERIES I \& II), AND AFTER (WEEKS 7) ADMINISTRATION OF L-AsE

\begin{tabular}{lcccccc}
\hline \multicolumn{7}{c}{ Mean (SD) } \\
\hline Variables & $\boldsymbol{\Delta}$ PT (sec) & P value & $\Delta$ aPTT (sec) & P value & $\Delta$ Fibrinogen $(\mathbf{m g} / \mathbf{d l})$ & P value \\
\hline At diagnosis & $3.8(2.59)$ & 0.58 & $6.43(7.06)$ & 0.000 & $-43.73(32.01)$ & 0.000 \\
Series I & $5.13(2.74)$ & 0.739 & $15.20(9.88)$ & & $-89.30(36.74)$ & 0.753 \\
Series II & $4.90(2.67)$ & 0.000 & $15.97(5.95)$ & 0.746 & $-85.60(37.34)$ & 0.000 \\
Weeks 7 & $-8.5(2.96)$ & & $-25.67(12.59)$ & & $68.20(32.45)$ &
\end{tabular}

results can be seen in Table 3. The values of PT and aPTT became normal and the fibrinogen level increased which were significantly tested against series II.

It is shown in Table 4 that there were no significant changes of $\Delta \mathrm{PT}$ at diagnosis compared to series I and II and of $\Delta \mathrm{PT}$ in series I compared to II but significant change of $\Delta \mathrm{PT}$ was observed in weeks $7 \mathrm{com}$ pared to series II. Meanwhile, there was a significant change of $\Delta \mathrm{aPTT}$ at diagnosis compared to series I but none between series I and II. Nevertheless, significant change of $\Delta \mathrm{aPTT}$ in weeks 7 to series II was detected.

There was significant change of $\boldsymbol{\Delta}$ fibrinogen value at diagnosis to series I (decreased level) and between series II to weeks 7 (increased level).

\section{Discussion}

There are three determinants for the pathogenesis of coagulation abnormalities in acute leukemia i.e,
(1) factors associated with leukemic cells (e.g. procoagulant as well as fibrinolytic expression of cytokines and tumor necrosis factor, which can affect the hemostatic balance of the endothelium); (2) the chemotherapy; and (3) the complication, mainly infection. ${ }^{14}$

It has been observed that the combination of chemotherapy may play a significant role in causing hemostatic abnormalities in ALL patients during their treatment. This was true, especially when L-Ase was used in combination with other drugs. ${ }^{3-7}$ L-Ase is an enzyme that has anti-neoplastic activity which hydrolyses L-asparagine in the host's blood resulting in the depletion of L-Ase, which is needed by specific tumor cells as an essential nutrient, and therefore inhibits proliferation of these cells. ${ }^{3-7,18}$

In a study by Gralnick et al involving patients with adult acute leukemia, L-Ase was used in the protocol, with a dose of 50-200 IU/kg i.v., for three days consecutively or with an interval of 4 days among the subjects. Twelve out of 26 subjects studied showed prolongation 
Djajadiman Gatot et al: Coagulation abnormality as a complication of L-asparginase therapy in ALL

of PT and aPTT until 21 days during chemotherapy. Decreased fibrinogen as well as plasminogen levels found in 13 subjects and 7 of them with fibrinogen levels lower than $200 \mathrm{mg} / \mathrm{dl} .{ }^{5}$ The prolongation of PT and aPTT as well as hypofibrinogenemia was also observed, after treatment with L-Ase alone or in combination with vincristine and prednisone. ${ }^{3,19}$ This was believed that L-Ase can suppress the coagulation proteins by breaking down L-asparagine to L-aspartic acid and cause depletion of amino acids and decrease synthesis of various proteins. 3,20 In another study by Homans et $\mathrm{al}^{2}$, L-Ase was used as a single agent when in complete remission in 12 pediatric patients with ALL and showed that changes in PT, aPTT, and fibrinogen, while statistically significant, remained within or close to normal range during the study, yet such results were not in accordance with that of our study as the changes of hemostatic parameters were beyond the normal range.

In this study, we used, as in our childhood ALL protocol, $6000 \mathrm{IU} / \mathrm{m}^{2}$ of L-Ase i.v., 3 times a week for 2 weeks and significant prolongation of PT and aPTT with decreased fibrinogen levels during the first and the second week of L-Ase were observed. These results are similar with that of L-Ase during the use with 5000-9000 IU/day for 1 week, along with vincristine and prednisone in the treatment of childhood ALL. ${ }^{21}$

Hypofibrinogenemia $(<100 \mathrm{mg} / \mathrm{dl})$ without prolongation of PT and aPTT were found in 4 adult ALL during administration of vincristine and prednisone with intrathecal methotrexate, yet without L-Ase. ${ }^{22}$ In another observation, hypofibrinogenemia had already been found in some patients with malignancies prior to the administration of L-Ase. ${ }^{23}$ This condition was possibly caused by sub-clinical consumption coagulopathy.

Our study showed that during the first week of L-Ase administration, prolongation of PT, aPTT, and hypofibrinogenemia began. The prolongation of activated partial thromboplastin time was maximal at weeks 3-4 (series I) while prolongation of PT and hypofibrinogenemia were maximal at weeks 5-6 (series II). These abnormalities were returned to normal after cessation of L-Ase by weeks 7 . The changes of hemostatic parameter were not uniformly seen. The prolongation of PT and aPTT were observed from day 3 to day 7 after commencement of L-Ase, while hypofibrinogenemia were commonly observed 1 week after L-Ase was given. 5,6,21
The abnormality of specific clotting factors was noted by Ramsay et al $^{3}$ in 16 children treated for ALL. They found that factor XI decreased by $<70 \%$ in 14 subjects and factor IX $<70 \%$ in 9 subjects. Other specific clotting factors, II, V, VII, VIII, X, and XII were not significantly depleted and due to limited facilities, such study was not performed in our subjects.

The effect of L-asparaginase on fibrinolysis activity was not studied in our patients again because of limited facilities, but Vellenga et al ${ }^{16}$ found that its activity decreased in 2-3 days after administration of L-Ase and returned to normal within 7 days of drug cessation.

Unlike other studies, in which a variety of bleeding as well as thrombosis were observed, ${ }^{8-10}$ we found neither additional hemorrhage nor consumption coagulopathy complications developed in any subjects during the remission induction of chemotherapy. It seems that the depletion of clotting and fibrinolytic factors are merely caused by mild to moderate temporary suppression in the production of those factors. However, the possibility of bleeding in children with acute leukemia in which several contributory factors are involved, should be kept in mind especially during the treatment with L-Ase.

In conclusion, although there are significant prolongation of prothrombin time, activated partial thromboplastin time, and reduction of fibrinogen level, it seems that when a shorter course of L-Ase used in the induction remission of intensive chemotherapy, no evidence of further hemostatic complications were observed. This is in accordance with the suggestion that many of the previously noted changes in plasma coagulation and platelet function associated with L-Ase may be dependent on the schedule of drug administration as well as other pharmacologic and hematologic factors. ${ }^{2}$ Further studies on the particular influence of L-Ase and other most active drugs on hemostatic mechanism will be necessary. The objective is to enhance the understanding of the circumstances, especially for the prediction and prevention of bleeding complication during intensive chemotherapy in children with leukemia.

\section{References}

1. Mohri H. Acquired von Willebrand disease and storage pool disease in chronic myelocytic leukemia. Am J Hematol 1986;22:391-401. 
2. Homans AC, Rybak ME, Baglini RL, Tiarks C, Steiner ME, Forman EN. Effect of L-asparaginase administration on coagulation and platelet function in children with leukemia. J Clin Oncol 1987;5:811-7.

3. Ramsay NK, Coccia PF, Krivit W, Nesbit ME, Edson JR. The effect of $\mathrm{L}$-asparaginase on plasma coagulation factors in acute lymphoblastic leukemia. Cancer 1977;40: 1398-401.

4. Sills RH, Nelson DA, Stockman JA. L-asparaginase-induced coagulopathy during therapy of acute lymphoblastic leukemia. Med Pediatr Oncol 1978;4:311-3.

5. Gralnick HR, Henderson E. Hypofibrinogenemia and coagulation factor deficiencies with $\mathrm{L}$-asparaginase treatment. Cancer 1971;27:1313-20.

6. Priest JR, Ramsay NK, Latchaw RE, Lockman LA, Hasegawa DK, Coates TD, et al. Thrombotic and hemorrhagic strokes complicating early therapy for childhood acute lymphoblastic leukemia. Cancer 1980;46:1548-54.

7. Priest JR,Ramsay NK, Bennett AJ, Krivit W, Edson JR. The effect of $\mathrm{L}$-asparaginase on antithrombin, plasminogen, and plasma coagulation during therapy for acute lymphoblastic leukemia. J Pediatr 1982;100:984-9.

8. Barrowcliffe TW, Kirkwood TB, Rizza CR. Alumunium hydroxide adsorption and factor VIII clotting assays. Lancet 1980;1:820.

9. Gralnick HR, Abrell E. Studies of the procoagulant and fibrinolytic activity of promyelocytes in acute promyelocitic leukemia. Br J Hematol 1973;24:89-99.

10. Gralnick HR, Sultan C. Annotation: Acute promyelocytic leukemia, haemorrhagic manifestation and morphologic criteria. Br J Hematol 1975;29:373-6.

11. Anderson N, Lokich JJ, Tullis JL. L-asparaginase effect on antithrombin-III levels. Med Pediatr Oncol 1979;7:335-40.

12. Buchanan GR, Holtkamp CA. Reduced antithrombin III levels during L-asparaginase therapy. Med Pediatr Oncol 1980;8:7-14.

13. Vellenga E, Mulder NH, Nieweg HO. Antithrombin III deficiency during asparaginase therapy. Lancet 1980;1:649-50.
14. Barbui T, Finazzi G, Falanga A. The management of bleeding and thrombosis in leukemia. In: Henderson ES, Lister TA, Greaves MF, editors. Leukemia: 6th ed. Philadelphia: Saunders, 1996. p. 291-300.

15. Pui CH, Jackson CW, Chesney CM, Lyles SA, Bowman WP, Abrowictch M, et al. Sequential changes in platelet function and coagulation in leukemic children treated with L-asparaginase, prednisone, and vincristine. J Clin Oncol 1983;1:380-5.

16. Vellenga E, Kluft C, Mulder NH, Wijngaards G, Nieweg HO. The influence of $\mathrm{L}$-asparaginase therapy on the fibrinolytic system. Br J Haematol 1984;57: 247-54.

17. Gatot D, Windiastuti E, Abdulsalam M, Munthe BG. Treatment of Childhood Acute Lymphoblastic Leukemia. The Jakarta Experience. Presented at the $17^{\text {th }}$ Asia Pacific Cancer Conference, Bali; 2003 October 8-11.

18. Jaffe N, Traggis L, Das WC, Das L, Moloney, Hann HW, Kim BS, et al. L-asparaginase in the treatment of neoplastic diseases in children. Cancer Res 1971;31:942-8.

19. Land VJ, Sutow WW, Fernbach DJ, Lane DM, Williams TE. Toxicity of L-asparaginase in children in advanced leukemia. Cancer 1972;30:339-43.

20. Pui CH, Chesney CM, Bergum PW, Jackson CW, Rappaport SI. Lack of pathogenic role of protein $\mathrm{C}$ and $\mathrm{S}$ in thrombosis associated with asparaginase-prednisone-vincristine therapy for leukemia. Br J Haematol 1986;64:283-90.

21. Saito M, Asakura H, Jokaji H, Uotani C, Kumabashiri I, Ito $\mathrm{K}$, et al. Changes in hemostatic and fibrinolytic proteins in patients receiving $\mathrm{L}$-asparaginase therapy. Am J Hematol 1989;32:20-3.

22. Al-Mondhiry H. Hypofibrinogenemia associated with vincristine and prednisone therapy in lymphoblastic leukemia. Cancer 1975;35:144-7.

23. Betticole RE, Himelstein ES, Oettgen HF, Clifford GO. Hypofibrinogenemia due to L-asparaginase: Studies on fibrinogen survival using autologous I-fibrinogen. Blood 1970;35:195-200. 